\title{
Tolerance Induction in Solid Organ Transplantation
}

National Cancer Institute

\section{Source}

National Cancer Institute. Tolerance Induction in Solid Organ Transplantation. NCI

Thesaurus. Code C156451.

An immunological environment, mediated by T-regulatory cells, favoring regulation, supporting graft survival, without interfering with crucial immune surveillance mechanisms and, concurrently, abolishing immunosuppressant-related toxicity. 